BMJ Open Sport \& Exercise Medicine

\title{
High-intensity exercise training does not influence body weight but improves lipid oxidation in obese adults: a 6-week RCT
}

\author{
Georges Jabbour, ${ }^{1}$ Horia-Daniel lancu ${ }^{2}$
}

To cite: Jabbour G, lancu H$D$. High-intensity exercise training does not influence body weight but improves lipid oxidation in obese adults: a 6-week RCT. BMJ Open Sport Exerc Med 2017;3:e000283.

doi:10.1136/bmjsem-2017000283

Accepted 22 August 2017

\section{(1) crossanak}

${ }^{1}$ Sport Science Program, College of Arts and Sciences, Qatar University, Doha, Qatar ${ }^{2}$ School of Kinesiology and Leisure, Faculty of Health Sciences and Community Services, Université de Moncton, Moncton, New Brunswick, Canada

\section{Correspondence to} Dr Georges Jabbour, Sport Science Program, College of Arts and Sciences, Qatar University, P.0.Box 2713, Doha, Qatar, Office Tel: +974 4403 4970;

georgesjabbour1980@ hotmail.com

\section{ABSTRACT}

Objectives This study examined the effects of 6 weeks of high-intensity training (HIT) on lipid oxidation (LO) rates during incremental exercises in obese adults.

Methods Twenty-four obese adults were randomised into a no-exercise control group ( $\mathrm{n}=12$; body mass index=33.3 (4.8) kg.m ${ }^{-2}$ ) and a HIT group (18 sessions of $6 \times 6 \mathrm{~s}$ of supramaximal cycling and $2 \mathrm{~min}$ passive intervals; $n=12$; body mass index=33.2 (2.8) kg. $\mathrm{m}^{-2}$ ). The percentage of $\mathrm{LO}$ contribution was computed at rest and for all workloads $(25,50,75$, 100 and $125 \mathrm{~W}$ ) in both groups before and after training via a graded maximal cycling test.

Results After training, the HIT group showed significantly higher $\mathrm{LO}$ at rest and at 25, 50 and $75 \mathrm{~W}$ compared with baseline $(p<0.01)$ and the control group $(p<0.01)$. Moreover, for the training group, the homoeostasis model assessment of insulin resistance (HOMA-IR) index decreased significantly from the baseline value $(p<0.01)$ and the control group value $(p<0.01)$. The increases in LO observed at rest and stages 25,50 and $75 \mathrm{~W}$ were positively correlated with the declines in the HOMA-IR index $(r=0.87, r=0.83$, $r=0.91$ and $r=0.88 ; p<0.01$ ).

Conclusion In obese adults, HIT increased lipid contributions to energy release at rest and in response to incremental exercise, while there were no changes in participants' aerobic capacity. This supports the hypothesis that metabolic changes rather than improved aerobic capacity are important to improve LO. Trial registration number ISRCTN66508384. Stage: post-results.

\section{INTRODUCTION}

Based on extensive evidence of health benefits, physical activity is widely recommended today for children and obese adults. ${ }^{1}$ However, with the lack of time frequently mentioned as the key barrier to physical activity participation, physical activity levels remain low. ${ }^{2}$ In terms of exercise efficacy, the main goals are to promote fat reduction by increasing lipid oxidation (LO) and to increase the ability of the skeletal muscle to

\section{What are the new findings}

- In response to high-intensity training, there was an $11 \%$ increase in lipid oxidation rates at rest among obese adults.

- High-intensity training increased lipid oxidation rates during incremental exercises in obese adults, while there were no changes in participants' aerobic capacity.

- Following high-intensity training, the amelioration in lipid oxidation observed at rest and stages 25, 50 and $75 \mathrm{~W}$ was positively associated with improved homoeostasis model assessment of insulin resistance.

How might it impact on clinical practice in the near future?

High-intensity training may serve as an exercise strategy for the obese sedentary population.

- High-intensity training offers a short-duration stimulus for obese individuals to increase fat oxidation at rest and during exercise.

- Metabolic indicators rather than improved aerobic capacity are important for improving lipid oxidation at rest and at different stages of incremental exercise in obese adults.

use lipids. ${ }^{3}$ Obese individuals have reduced LO in skeletal muscle ${ }^{4}{ }^{5}$ which is attributed in part to insulin resistance. ${ }^{6} 7$ However, other studies reported higher fat oxidation during exercise in obese individuals than in non-obese individuals. ${ }^{8}$

The role of high-intensity training (HIT) has become increasingly popular in the context of obesity management, based on a number of metabolic improvements (an increase in resting fat oxidation rate and a decrease in resting carbohydrate oxidation in the fasting state compared with baseline) that have been achieved in response to this 
training. ${ }^{9} 10$ To date, the most used protocol is the Wingate test (30 s of all-out sprinting). However, it seems that such a protocol is extremely difficult for some participants who feel discomfort. On the contrary, outdoor testing has been shown to be more motivational to participants. ${ }^{11}$ In a recent study, Racil et $a l^{11}$ on an outdoor athletics track reported that HIT $(15 \mathrm{~s})$ at $100 \%$ of maximal aerobic speed (MAS) induced better results in body composition and in the rate of perceived exertion at maximal effort in obese female adolescents, compared with training at moderate intensity ( $80 \%$ of MAS). In addition, Jabbour et $a l^{12}$ evaluated the acute effect of a new form of exercise (very brief-6s), which has been shown to be tolerable for experimental subjects and was indeed able to enhance LO. More other studies have also shown that HIT improved insulin sensitivity. ${ }^{13-15}$ In addition, Whyte et $a l^{9}$ reported increased lipolysis at rest after only 2 weeks of intense training intervals in sedentary overweight/obese men (body mass index $\left.(\mathrm{BMI})=31.0(3.7) \mathrm{kg} \cdot \mathrm{m}^{-2}\right)$. However, few data exist concerning the $\mathrm{LO}$ rates during exercise in highintensity-trained obese subjects.

Therefore, we aimed to evaluate the effects of 6 weeks of HIT on the LO rate at rest and during incremental exercises in obese adults. Furthermore, we tried to determine whether aerobic capacity and/or metabolic changes were associated with better LO.

\section{MATERIALS AND METHODS}

The recruitment took place within the Moncton campus of the Université de Moncton, where 33 young adults (18 women and 15 men) who met the inclusion criteria were invited to voluntarily participate in the project. The University's Human Research Ethics Committee (UHRC) approved the study protocol, following all procedures from the Declaration of Helsinki of $1975,{ }^{16}$ as revised in 2008. Before acceptance in the study, all participants gave their informed consent. The inclusion criteria for participation were as follows: in addition to being obese, the participants had to be sedentary (participating in $<60$ min.week $^{-1}$ of structured exercise, as assessed by the International Physical Activity Questionnaire ${ }^{17}$ ) and not taking part in any systematic exercise training at the enrolment or during the 6 months prior to the experiment; moreover, they had no history of cardiovascular or other chronic disease and no history of drug consumption or smoking before the study.

Each participant was thoroughly familiarised with testing procedures and equipment before entering the protocol. In the present study, to reduce and control the potential effect of ovarian hormones on substrate metabolism in women, we controlled for the phase within the menstrual cycle (follicular phase) and the oral contraceptives.

The protocol started with two sessions of preliminary testing to define baseline levels of key variables (baseline testing). The testing was carried out on two different days (day 1 (D1) and day 2 (D2)) after an overnight fast and took place in the morning of each day ( 08:30). A minimum of 48 hours separated the 2 days of testing, and all participants were asked to avoid physical activity for 48 hours before each session. Each participants recorded a 48 -hour food diary prior to the intervention and during the final days of testing (postintervention). During the 6 weeks of intervention, none of the participants left the training sessions and no other difficulties were encountered.

\section{Anthropometric measurements}

Body mass, body fat percentage, fat-free mass (FFM) and fat mass were assessed using a bioimpedance machine (Vacumed, Bodystat1500, Isle of Man, British Isles). According to our laboratory results, the intraassay and interassay coefficients of variations $(\mathrm{CVs})$ were $1.3 \%-1.6 \%$ and $1.1 \%-1.8 \%$, respectively. Height was determined to the nearest $0.5 \mathrm{~cm}$ with a measuring tape fixed to the wall. BMI was calculated as the ratio of mass $(\mathrm{kg})$ to height squared $\left(\mathrm{m}^{2}\right)$. Following the determination of body composition, obese participants $\left(\mathrm{BMI}>30 \mathrm{~kg} / \mathrm{m}^{2}\right)$ were selected based on the Canadian guidelines for body weight classification in adults. ${ }^{18}$

\section{Physiology assessment}

At baseline on D1, after a 12-hour overnight fast, each participant reclined into a supine position for $10 \mathrm{~min}$ before venous blood samples from an antecubital vein were drawn at rest and collected in a vacutainer tube containing EDTA. Subsequently, participants performed a maximal test on an upright cycle ergometer (Monark ergomedic 839E electronic test cycle, Sweden) with continuous measurement of pulmonary gas exchange using a breath-by-breath automated metabolic system (Ergocard MEDI-SOFT, Sorinnes, Belgium) to determine their maximal oxygen consumption $\left(\mathrm{VO}_{2 \max }\right)$ according to criteria established by Spiro. ${ }^{19}$ The test began with an initial power of 25 $\mathrm{W}$ and was progressively increased by $25 \mathrm{~W}$ every $5 \mathrm{~min}$ until exhaustion. During this maximal test, the heart rate values were continuously measured using an ECG machine (CASE 16 exercise testing system, Marquette, Wisconsin, USA).

In the present study, only participants who reached exhaustion at $125 \mathrm{~W}$ at baseline testing were selected. Therefore, those who could not achieve a power output equal to $125 \mathrm{~W}(\mathrm{n}=9)$ were excluded from the total of 33 participants. Consequently, for each stage, all participants pedalled at the same relative intensity to $\mathrm{VO}_{2 \max }$.

On D2, after 10 min of warm-up, the selected participants completed a force-velocity test on a cycle ergometer using a technique adapted from the study of Vandewalle et al. ${ }^{20}$ This test involves a succession of approximately $6 \mathrm{~s}$ supramaximal bouts, with flywheel resistance increasing by $1 \mathrm{~kg}$ after each bout until the 
subject is unable to perform the test. A 5 min passive recovery was used between successive bouts. For each bout, the peak velocity was recorded and the power output was calculated by multiplying the load with the speed. The optimal load corresponded to the load at which maximal power $\left(\mathrm{PO}_{\max }\right)$ was achieved. This load was then used for the training protocol that followed. The force-velocity test was also completed every 2 weeks to adjust the individual power level of supramaximal cycling exercise (SCE). The 2 days of testing took place before the HIT (baseline testing) and again at the end of the training period (postintervention), following the same procedures. The final sample for our study consisted of 24 participants, including 13 women and 11 men. Women represented $58 \%$ of the total sample compared to $42 \%$ for men. To ensure that the population was well represented, we used the stratified random method based on gender. Therefore, we created a numbered list of individuals by gender, and the number was determined to be chosen in each stratum. Subsequently, we used simple random sampling to select participants within each stratum. A frame numbered from 1 to 13 for women and from 1 to 11 for men was randomly used to choose the individuals who were part of the following two groups: the control group (without any intervention; $n=12$ ) and the training group $(n=12)$.

\section{HIT protocol}

Once participants completed the preliminary testing, a total of 18 training sessions were prescribed for the training group (three sessions per week for 6 weeks). Each of the sessions began with a 5 min warm-up of continuous cycling at moderate intensity corresponding to $40 \%-50 \%$ of their $\mathrm{HR}_{\max }$ and was followed by six repetitions of SCE intervals with $2 \mathrm{~min}$ of passive recovery between each repetition. Each SCE repetition continued for $6 \mathrm{~s}$, and the participants were asked to pedal at maximal velocity against the resistance that was determined on D2. The heart rate values were recorded during all the training sessions using a heart rate monitor (Polar, Kempele, Finland). The total duration of each session was approximately $15 \mathrm{~min}$. During the training sessions, the velocity (in rotations per minute) was recorded for each second of the entire round to ensure that participants pedalled at their maximal capacity. After concluding the 6 weeks of training, the participants were asked to return for the final days of testing (postintervention), when the procedures of D1 and D2 were repeated and the posttraining data were collected.

Throughout the intervention, the subjects were asked to abstain from consuming alcohol and encouraged to continue their normal diet and maintain their typically sedentary behaviour.

\section{Calculation of relative lipid contribution}

The \%LO to the energy yield was computed at D1 across the maximal exercise (see the Physiology assessment section) using a gas exchange measurement according to the non-protein respiratory quotient technique as follows: \%LO $=[(1-$ respiratory exchange ratio) $/ 0.29] \cdot 100 .^{21}$ To measure $\mathrm{LO}$ at rest, before performing the maximal test, the participants remained seated for $5 \mathrm{~min}$ on the bicycle ergometer in the same position used in subsequent exercises. Before performing the maximal test, resting oxygen consumption was measured for each participant based on the mean oxygen consumption of the last $30 \mathrm{~s}$ of minutes 3, 4 and 5. To assess LO at each stage of maximal exercise, the oxygen consumption $\left(\mathrm{VO}_{2}\right)$ and carbon dioxide production $\left(\mathrm{VCO}_{2}\right)$ average values were directly measured by pulmonary gas exchange using a breath-by-breath automated metabolic system (Ergocard MEDI-SOFT, Sorinnes, Belgium) during the last minute of each stage with $\mathrm{VO}_{2}$ and $\mathrm{VCO}_{2}$ at a steady state. Moreover, the LO rates were also calculated in milligrams per minute using the equation of Péronnet and Massicotte ${ }^{22}$ as follows: Lipid $\left(\right.$ g. $\left.\min ^{-1}\right)=-1.7012$ $\mathrm{VCO}_{2}+1.6946 \mathrm{VO}_{2}$ and converted to $\left(\mathrm{mg} \cdot \mathrm{min}^{-1}\right)$ and normalised to FFM. The LO values were only considered at 25, 50 and $75 \mathrm{~W}$ because at the two highest workloads (100 and $125 \mathrm{~W})$, LO values were equal to $0 \%$.

\section{Biochemical analysis}

Commercially available kits were used to determine plasma glucose (all ABX Pentra, Montpellier, France). A single analyser run was used for each subject, and each sample was analysed twice. The intra-assay CV was $1.7 \%$. Plasma insulin concentrations were measured in the centralised laboratory by a radio-immunoassay procedure (Phaadebas Insulin Kit; Pharmacia Diagnostics AB, Piscataway, New Jersey, USA). The intra-assay and interassay CVs were $3.3 \%-4.0 \%$ and $3.7 \%-4.8 \%$, respectively. The insulin resistance was estimated by the homoeostasis model assessment (HOMA-IR) index as [fasting insulin $(\mu \mathrm{U} / \mathrm{mL}) \times$ fasting glucose $(\mathrm{mmol} / \mathrm{L})] /$ 22.5. ${ }^{23}$ Postintervention metabolic measurements were conducted approximately 72 hours following the final training session to understand if these observed improvements represented a transit response to the final high-intensity exercise session or a chronic response to the training programme. ${ }^{9} 20$

\section{Statistical analyses}

Statistical comparisons were performed between the control group and the training group two times (before and after training). Before analysis, all data were tested for normality (Kolmogorov-Smirnov test). For normally distributed data, intergroup and intragroup comparisons of the variables were computed by two-way ANOVA (group vs time) with repeated measurements 
Table 1 Anthropometric data before and at the postintervention period

\begin{tabular}{|c|c|c|c|c|}
\hline & \multicolumn{2}{|l|}{ Preintervention (baseline) } & \multicolumn{2}{|l|}{ Postintervention } \\
\hline & Control $(n=12)(f=7, m=5)$ & Trained $(n=12)(f=6, m=6)$ & Control $(n=12)(f=7, m=5)$ & Trained $(n=12)(f=6, m=6)$ \\
\hline Age (year) & 23.1 (3.3) & $22.5(2.3)$ & $23.3(2.3)$ & $22.7(2.2)$ \\
\hline Height (cm) & $1.71(0.11)$ & $1.74(0.09)$ & $1.71(0.11)$ & $1.74(0.09)$ \\
\hline Body mass (kg) & $99.5(24.1)$ & $101.1(21.1)$ & $100.5(21.1)$ & $99.9(9.1)$ \\
\hline BMI & $33.3(4.8)$ & $33.2(2.8)$ & $33.7(3.8)$ & $33.1(3.7)$ \\
\hline FM (\%) & $42.3(9.4)$ & $42.8(7.4)$ & $44.3(9.4)$ & $42.1(7.1)$ \\
\hline FM (kg) & $48.3(10.1)$ & $50.9(11.1)$ & $49.2(9.3)$ & $49.1(6.1)$ \\
\hline FFM (kg) & $51.2(6.1)$ & $50.2(2.8)$ & $51.3(2.6)$ & $50.8(3.7)$ \\
\hline
\end{tabular}

Values are mean \pm SD.

BMI, body mass index; f, female; FFM: fat-free mass; FM, fat mass; m, men.

to determine the main and interaction effects between groups over time. One-way ANOVA was used to determine the differences between groups.

Bonferroni's post hoc test was performed. Pearson correlations were used to assess the association between changes in the LO rate and changes in maximal oxygen consumption, insulin resistance index, BMI and FFM. A value of $p<0.05$ was set as the level of statistical significance. Analyses were performed using IBM-SPSS Statistics V.19 software.

\section{RESULTS}

After HIT (postintervention), the $\mathrm{VO}_{2 \max }$ values expressed in absolute and in relative terms did not differ significantly from those at baseline. Height, body mass, BMI, fat mass and FFM were similar across the two groups at baseline and postintervention (table 1). Following the HIT, the LO expressed in $\%$ and in milligrams per minute of FFM of the energy yield at rest was significantly higher $( \pm 11 \%)$ compared with that observed at baseline $(\mathrm{p}<0.01)$ (table 2$)$, and it was significantly different compared with that of the control group at baseline $(\mathrm{p}<0.01)$ and at the postintervention $(\mathrm{p}<0.01)$ (table 3). Moreover, the LO values determined at 25,50 and $75 \mathrm{~W}$ of the incremental exercise increased significantly $(+20 \%$ at $25 \mathrm{~W} ;+21 \%$ at $50 \mathrm{~W} ;+14 \%$ at $75 \mathrm{~W})$ in the trained group $(\mathrm{p}<0.01)$ and were significantly higher than the values for the control group that were obtained at baseline $(p<0.01)$ and at postintervention $(\mathrm{p}<0.01)$ (tables 2 and 3 and figure 1). A significant time $\times$ group interaction effect for LO was observed at rest $(\mathrm{p}<0.01)$ and at 25 $(\mathrm{p}<0.01), 50(\mathrm{p}<0.01)$ and $75 \mathrm{~W}(\mathrm{p}<0.01)$ of the incremental exercise (table 3 ).

In this study, no associations were observed with changes in LO and anthropometry (BMI: $r=0.04$, $\mathrm{p}=0.4$; FFM: $\mathrm{r}=0.08, \mathrm{p}=0.7)$ or maximal oxygen consumption $(\mathrm{r}=0.02, \mathrm{p}=0.6)$. However, the increases in LO observed at rest and stages 25, 50 and $75 \mathrm{~W}$ were positively correlated with declines in the HOMA-
IR index $(r=0.87, r=0.83, r=0.91$ and $r=0.88$; $\mathrm{p}<0.01)$.

\section{DISCUSSION}

To our knowledge, this study is the first to examine the effect of HIT on \%LO and LO relative to FFM in obese adults at rest and during incremental exercise. Our results showed that HIT increased lipid contributions to energy release at rest and in response to incremental exercise. The increase in LO rates was associated to metabolic changes, while there was no improvement in maximal oxygen consumption. Our

(A) Training

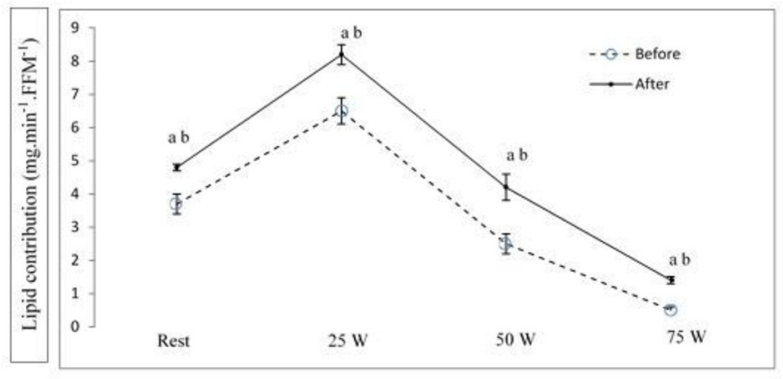

(B) Control

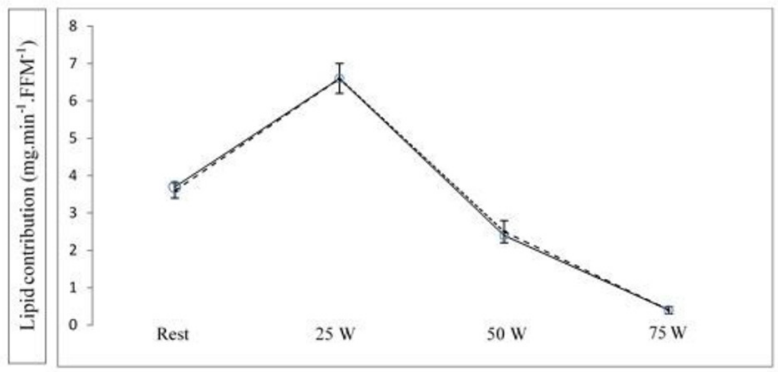

Values are mean $=\mathrm{SD}$ (standard deviation).

Significant difference between groups ( $a: p<0.01)$, Significant difference from Visit 1 ( $0: p<0.01$ ).

Figure 1 Lipid contribution at rest and during exercise in the training group $(\mathrm{A})$ and in the control group $(\mathrm{B})$ before and after the 6 -week high-intensity training period. FFM, fat-free mass. 
Table 2 Metabolic profiles and the respective contribution of lipid to total energy yield at rest and during exercise

\begin{tabular}{|c|c|c|c|c|}
\hline & \multicolumn{2}{|c|}{ Preintervention (baseline) } & \multicolumn{2}{|l|}{ Postintervention } \\
\hline & $\begin{array}{l}\text { Control }(n=12)(f=7 \text {, } \\
m=5)\end{array}$ & $\begin{array}{l}\text { Trained }(n=12)(f=6, \\
m=6)\end{array}$ & $\begin{array}{l}\text { Control }(n=12)(f=7 \text {, } \\
m=5)\end{array}$ & $\begin{array}{l}\text { Trained }(n=12)(f=6 \text {, } \\
m=6)\end{array}$ \\
\hline \multicolumn{5}{|l|}{ Aerobic fitness indicators } \\
\hline HR peak (beats. $\min ^{-1}$ ) & $196(12)$ & $196(09)$ & $197(16)$ & $198(12)$ \\
\hline RER peak & $1.1(0.1)$ & $1.1(0.3)$ & $1.1(0.3)$ & $1.1(0.2)$ \\
\hline $\mathrm{VO}_{2 \max }\left(\right.$ L. $\left.\min ^{-1}\right)$ & $2.3(0.3)$ & $2.2(0.4)$ & $2.3(0.4)$ & $2.3(0.1)$ \\
\hline $\mathrm{VO}_{2 \max }\left(\mathrm{mL} \cdot \mathrm{min}^{-1} \cdot \mathrm{kg}^{-1}\right)$ & $23.4(8.4)$ & $22.6(6.4)$ & $22.2(7.4)$ & $23.1(6.1)$ \\
\hline \multicolumn{5}{|l|}{ Metabolic analysis } \\
\hline Glucose (mmol/L) & $4.61(0.11)$ & $4.64(0.12)$ & $4.64(0.15)$ & $4.32(0.22)^{\star \star}$ \\
\hline Insulin $(\mu \mathrm{mol} / \mathrm{mL})$ & $22.6(4.6)$ & $23.2(4.6)$ & $23.2(4.6)$ & $13.8(3.3)^{\star \star}$ \\
\hline HOMA-IR & $4.63(1.7)$ & $4.78(1.2)$ & $4.78(1.2)$ & $2.65(1.5)^{\star \star}$ \\
\hline \multicolumn{5}{|l|}{ Lipid contribution (\%) } \\
\hline Rest & $58(10)$ & $57(9)$ & $57(11)$ & $68(4)^{\star \star}$ \\
\hline $25 \mathrm{~W}$ & $47(9)$ & $47(8)$ & $48(10)$ & $73(13)^{\star \star}$ \\
\hline $50 \mathrm{~W}$ & $23(5)$ & $24(5)$ & $24(5)$ & $45(5)^{\star \star}$ \\
\hline $75 \mathrm{~W}$ & $11(2)$ & $11(4)$ & $11(4)$ & $25(2)^{\star \star}$ \\
\hline
\end{tabular}

Values are mean \pm SD.

${ }^{* \star} \mathrm{p}<0.01$; significant difference from baseline.

$\mathrm{f}$, female; HOMA-IR, homoeostasis model assessment index of insulin resistance; HR, heart rate; m, men; RER, respiratory exchange ratio;

$\mathrm{VO}_{2 \max }$, maximal oxygen consumption.

results suggest that metabolic changes rather than improved aerobic capacity may constitute an important factor for improved LO after 6 weeks of supramaximal exercise cycling.

The present results show that changes in $\mathrm{VO}_{2 \max }$ did not differ between the two groups. Our results are in line with those of Thorstensson et $a l^{16}$ and Linossier et $a l^{24}$ using exclusively short sprint training. However, other studies showed increased maximal oxygen consumption after 2 weeks using supramaximal intensity intervention in overweight/obese individuals ${ }^{9}$ or after 6 weeks in healthy but sedentary young men and women who completed brief 'all-out' sprints $(10 \mathrm{~s}$ in week $1,15 \mathrm{~s}$ in weeks $2-3$ and $20 \mathrm{~s}$ in the final 3 weeks). ${ }^{25}$ For Whyte et $a l,{ }^{9}$ the increase in oxygen consumption obtained after 2 weeks of training was related to increases in mitochondrial enzyme activity. In the study of Metcalfe et $a l,{ }^{25}$ each training session consisted of low-intensity cycling $(60 \mathrm{~W})$ followed by all-out cycling sprints. This training combination does not allow us to isolate as to the effect of each component (low intensity vs high intensity) on aerobic capacity in training subjects. Therefore, the magnitude and direction of change in many variables (fitness indicators, health parameters) depend on the nature of the training protocol (ie, the frequency, intensity and duration of sprint efforts and the recovery between bouts).
Although the American College of Sports Medicine position stands on exercise intervention strategies to promote weight loss, several studies have been shown to have enhanced health benefits for important risk factors among obese and overweight individuals without any effect on overall weight loss. ${ }^{26} 27$ In the present study, no change in body weight is reported among trained group. In fact, the literature is clear that caloric restriction is more likely to result in significant weight loss compared with exercise training alone. ${ }^{28}$ Therefore, augmenting the energy expenditure by exercise training may affect changes in weight. However, a question often encountered is how much exercise is needed to lose weight and what type of exercise training should be performed.

In response to HIT, there was an $11 \%$ increase in LO rates at rest. Moreover, the $\mathrm{LO}$ rates at 25, 50 and 75 $\mathrm{W}$ and LO in mg.min ${ }^{-1} \mathrm{FFM}^{-1}$ at 25, 50 and $75 \mathrm{~W}$ increased significantly compared with the preintervention values in the experimental group and were higher than the control group. Previous studies found altered substrate utilisation in obese individuals, manifested by increased resting $\mathrm{LO}^{4}$ and decreased LO during submaximal exercise. ${ }^{29}$ The cross-sectional study of Pérez-Martin et $a l^{29}$ showed that overweight people exhibited lower fat oxidation ability and an earlier shift from lipid to CHO-derived fuel at different exercise intensity compared with people of normal weight. 
Table 3 Percentage changes between baseline and postintervention in each group

\section{$\Delta$ Post vs pre for control group \\ $\Delta$ Post vs pre for trained group \\ Group*time effects \\ F $\quad$ p}

\begin{tabular}{|c|c|c|c|c|}
\hline \multicolumn{5}{|l|}{ Age and anthropometrics } \\
\hline Age (year) & 0.2 & 0.2 & 1.7 & 0.32 \\
\hline Height $(\mathrm{cm})$ & - & - & 1.6 & 0.33 \\
\hline Body mass (kg) & 1 & -1.1 & 1.2 & 0.29 \\
\hline BMI & 0.4 & -0.1 & 0.4 & 0.63 \\
\hline FM (\%) & 2 & -0.6 & 1.1 & 0.28 \\
\hline $\mathrm{FM}(\mathrm{kg})$ & 0.9 & -1.8 & 1.2 & 0.31 \\
\hline FFM (kg) & -0.3 & -0.4 & 1.3 & 0.29 \\
\hline \multicolumn{5}{|l|}{ Aerobic fitness indicators } \\
\hline HR peak (beats.min ${ }^{-1}$ ) & 1 & -2 & 1.4 & 0.36 \\
\hline RER peak & - & - & 1.3 & 0.39 \\
\hline $\mathrm{VO}_{2 \max }\left(\mathrm{L} \cdot \mathrm{min}^{-1}\right)$ & - & 0.1 & 1.1 & 0.18 \\
\hline $\mathrm{VO}_{2 \max }\left(\mathrm{mL} \cdot \mathrm{min}^{-1} \cdot \mathrm{kg}^{-1}\right)$ & -1.2 & 0.5 & 1.2 & 0.29 \\
\hline \multicolumn{5}{|l|}{ Metabolic analysis } \\
\hline Glucose (mmol/L) & 0.03 & $-0.29^{* *}$ & 11.8 & $<0.01$ \\
\hline Insulin $(\mu \mathrm{mol} / \mathrm{mL})$ & 0.6 & $-9.4^{\star \star}$ & 19.6 & $<0.01$ \\
\hline HOMA-IR & 0.15 & $-2.13^{\star *}$ & 21.8 & $<0.01$ \\
\hline Rest & -1 & $11^{\star \star}$ & 12.1 & $<0.01$ \\
\hline \multicolumn{5}{|l|}{ Lipid contribution (\%) } \\
\hline $25 \mathrm{~W}$ & -1 & $20^{\star *}$ & 22.6 & $<0.01$ \\
\hline $50 \mathrm{~W}$ & 1 & $21^{* *}$ & 22.8 & $<0.01$ \\
\hline $75 \mathrm{~W}$ & - & $14^{\star *}$ & 19.8 & $<0.01$ \\
\hline
\end{tabular}

$\Delta$ The variation between parameters assessed at baseline (preintervention) and postintervention.

${ }^{\star *} \mathrm{p}<0.01$; significant difference from control group.

BMI, body mass index; FM, fat mass; FFM, fat-free mass; HOMA-IR, homoeostasis model assessment index of insulin resistance; HR, heart rate; $\mathrm{RER}$, respiratory exchange ratio; $\mathrm{VO}_{2 \max }$, maximal oxygen consumption.

The current study results showed a significant increase during exercise of the LO as a percentage of total energy used and relative to FFM. In response to endurance training, the results showed an increase in LO, which has reflected by an increase in mitochondrial density and a change in mitochondrial function, ${ }^{30}$ which seems necessary for realising the increased potential for aerobic ATP provision. ${ }^{31}$ However, in this study, there was no change in maximal $\mathrm{VO}_{2}$ values following 6 weeks of HIT. It is likely that, in the present work, the increased lipid contribution to energy yield may be related to the improvements of insulin resistance index. Indeed, in the obese individuals, altered glucose metabolism was observed at rest, which led to decreased basal LO. During exercise, an alteration in glycolytic flux from hyperglycaemia and hyperinsulinaemia reduces LO. ${ }^{32}$ However, HIT may improve glycolysis by increasing insulin sensitivity, ${ }^{9}$ reducing the blood glucose concentration and increasing glucose uptake into muscle. ${ }^{33}$ As shown in the present study, the improved HOMA-IR indicates an exercise-induced improvement in lipid metabolism achieved by improved regulation of plasma insulin reflecting increased basal LO and LO during incremental exercise, compared with baseline values. Therefore, HIT offers a short-duration stimulus for obese individuals to increase fat oxidation during exercise, and this adaptation appears to be partly attributed to glycolysis enhancement, given that this model of exercise training improves glycolytic activity. ${ }^{34}$

However, there are some limitations in the current study. First, only participants who reached exhaustion at $125 \mathrm{~W}$ at baseline testing were selected. Therefore, those who could not achieve a power output equal to $125 \mathrm{~W}(\mathrm{n}=9)$ were excluded from the total of 33 participants. Consequently, it will be interesting to address 
how LO rates varies among individuals with different fitness profiles. The results obtained included men and women in the same study group. Given that sex could have affected our results, further studies are needed to address this effect. Second, the missing postexercise changes in several metabolic and hormonal parameters (eg, catecholamine) may allow us to better understand the effect of such exercise on LO adaptations in comparison of other training group such continuous training. Finally, as the energy intake throughout the training period was not directly controlled during the study, we cannot be sure if our instructions were fully respected.

\section{CONCLUSIONS}

In obese adults, HIT improved LO at rest and in response to incremental exercise. Metabolic indicators rather than improved aerobic capacity were important for improving LO at rest and at different stages of incremental exercise in obese adults. This novel model of HIT might be an appropriate physical activity option for obese persons and may, in return, help clarify why obese people require HIT as part of their multi-component treatment for obesity. However, further studies are needed to identify the optimal combination of training intensity and volume necessary to induce adaptations in a practical time-efficient manner.

Contributors GJ was responsible for conception and design; acquisition, analysis and interpretation of data. HDI contributed to the acquisition and the interpretation of data.

Funding Faculty of Superior Studies and Research of the Universite de Moncton.

Competing interests None declared.

Patient consent Obtained.

Ethics approval University's Human Research Ethics Committee.

Provenance and peer review Not commissioned; externally peer reviewed.

Open Access This is an Open Access article distributed in accordance with the Creative Commons Attribution Non Commercial (CC BY-NC 4.0) license, which permits others to distribute, remix, adapt, build upon this work noncommercially, and license their derivative works on different terms, provided the original work is properly cited and the use is non-commercial. See: http:// creativecommons.org/licenses/by-nc/4.0/

(C) Article author(s) (or their employer(s) unless otherwise stated in the text of the article) 2017. All rights reserved. No commercial use is permitted unless otherwise expressly granted.

\section{REFERENCES}

1. Garber CE, Blissmer B, Deschenes MR, et al. American College of Sports Medicine position stand. Quantity and quality of exercise for developing and maintaining cardiorespiratory, musculoskeletal, and neuromotor fitness in apparently healthy adults: guidance for prescribing exercise. Med Sci Sports Exerc 2011;43:1334-59.

2. Reichert FF, Barros AJ, Domingues MR, et al. The role of perceived personal barriers to engagement in leisure-time physical activity. Am J Public Health 2007;97:515-9.

3. Moro C, Pillard F, De Glisezinski I, et al. Training enhances ANP lipid-mobilizing action in adipose tissue of overweight men. Med Sci Sports Exerc 2005;37:1126-32.
4. Kim JY, Hickner RC, Cortright RL, et al. Lipid oxidation is reduced in obese human skeletal muscle. Am J Physiol Endocrinol Metab 2000;279:E1039-44

5. Colberg SR, Simoneau JA, Thaete FL, et al. Skeletal muscle utilization of free fatty acids in women with visceral obesity. $J$ Clin Invest 1995;95:1846-53.

6. Goodpaster BH, Katsiaras A, Kelley DE. Enhanced fat oxidation through physical activity is associated with improvements in insulin sensitivity in obesity. Diabetes 2003;52:2191-7.

7. Goodpaster BH, Kelley DE, Wing RR, et al. Effects of weight loss on regional fat distribution and insulin sensitivity in obesity. Diabetes 1999;48:839-47.

8. Ara I, Larsen S, Stallknecht B, et al. Normal mitochondrial function and increased fat oxidation capacity in leg and arm muscles in obese humans. Int J Obes 2011;35:99-108.

9. Whyte LJ, Gill JM, Cathcart AJ. Effect of 2 weeks of sprint interval training on health-related outcomes in sedentary overweight/obese men. Metabolism 2010;59:1421-8.

10. Bayati M, Farzad B, Gharakhanlou R, et al. A practical model of lowvolume high-intensity interval training induces performance and metabolic adaptations that resemble 'all-out' sprint interval training $J$ Sports Sci Med 2011;10:571-6.

11. Racil G, Coquart JB, Elmontassar W, et al. Greater effects of highcompared with moderate-intensity interval training on cardiometabolic variables, blood leptin concentration and ratings of perceived exertion in obese adolescent females. Biol Sport 2016;33:145-52.

12. Jabbour G, lancu HD, Paulin A, et al. Effects of acute supramaximal cycle exercise on plasma FFA concentration in obese adolescent boys. PLoS One 2015;10:e0129654.

13. Burgomaster KA, Howarth KR, Phillips SM, et al. Similar metabolic adaptations during exercise after low volume sprint interval and traditional endurance training in humans. J Physio/ 2008;586:151-60.

14. Nybo L, Sundstrup E, Jakobsen MD, et al. High-intensity training versus traditional exercise interventions for promoting health. Med Sci Sports Exerc 2010;42:1951-8.

15. Babraj JA, Vollaard NB, Keast $C$, et al. Extremely short duration high intensity interval training substantially improves insulin action in young healthy males. BMC Endocr Disord 2009;9:3

16. Thorstensson A, Sjödin B, Karlsson J. Enzyme activities and muscle strength after "sprint training" in man. Acta Physiol Scand 1975;94:313-8.

17. Craig CL, Marshall AL, Sjöström M, et al. International physical activity questionnaire: 12 -country reliability and validity. Med Sci Sports Exerc 2003;35:1381-95.

18. Canadian Guidelines for Body Weight Classification in Adults-Quick Reference Tool for Professionals. 2007 http://www.hc-sc.gc.ca/fnan/nutrition/weights-poids/guide-ld-adult/cg_quick_ref-ldc_rapide_ ref-eng.php; (accessed 16.09.2007).

19. Spiro SG. Exercise testing in clinical medicine. Br J Dis Chest 1977;71:145-72.

20. Vandewalle HPG, Heller J, Monod H. Interests and limits of the speed-force relation in human. Science and Movement 1988;4:38-46.

21. McGilvery RW, Goldstein GW. Biochemistry: a function approach Philadelphia: Saunders 1983:810-976.

22. Péronnet $F$, Massicotte D. Table of nonprotein respiratory quotient an update. Can J Sport Sci 1991;16:23-9.

23. Matthews DR, Hosker JP, Rudenski AS, et al. Homeostasis model assessment: insulin resistance and beta-cell function from fasting plasma glucose and insulin concentrations in man. Diabetologia 1985;28:412-9.

24. Linossier MT, Denis C, Dormois D, et al. Ergometric and metabolic adaptation to a 5-s sprint training programme. Eur J Appl Physiol Occup Physiol 1993;67:408-14.

25. Metcalfe RS, Babraj JA, Fawkner SG, et al. Towards the minimal amount of exercise for improving metabolic health: beneficial effects of reduced-exertion high-intensity interval training. Eur J Appl Physiol 2012;112:2767-75

26. Donnelly JE, Blair SN, Jakicic JM, et al. Appropriate physical activity intervention strategies for weight loss and prevention of weight regain for adults. Medicine \& Science in Sports \& Exercise 2009;41:459-71.

27. Church TS, Blair SN, Cocreham S, et al. Effects of aerobic and resistance training on hemoglobin A1c levels in patients with type 2 diabetes: a randomized controlled trial. JAMA 2010;304:2253-62.

28. Miller WC, Koceja DM, Hamilton EJ. A meta-analysis of the past 25 years of weight loss research using diet, exercise or diet plus exercise intervention. Int J Obes Relat Metab Disord 1997;21:941-7. 
29. Pérez-Martin A, Dumortier M, Raynaud E, et al. Balance of substrate oxidation during submaximal exercise in lean and obese people. Diabetes Metab 2001;27:466-74.

30. Bruce CR, Thrush AB, Mertz VA, et al. Endurance training in obese humans improves glucose tolerance and mitochondrial fatty acid oxidation and alters muscle lipid content. Am J Physiol Endocrinol Metab 2006;291:E99-107.

31. Robinson DM, Ogilvie RW, Tullson PC, et al. Increased peak oxygen consumption of trained muscle requires increased electron flux capacity. J Appl Physiol 1994;77:1941-52.
32. Coyle EF, Jeukendrup AE, Wagenmakers AJ, et al. Fatty acid oxidation is directly regulated by carbohydrate metabolism during exercise. Am J Physiol 1997;273:E268-75.

33. Jensen J, Jebens E, Brennesvik EO, et al. Muscle glycogen inharmoniously regulates glycogen synthase activity, glucose uptake, and proximal insulin signaling. Am J Physiol Endocrinol Metab 2006;290:E154-62.

34. Dawson B, Fitzsimons M, Green S, et al. Changes in performance, muscle metabolites, enzymes and fibre types after short sprint training. Eur J Appl Physiol Occup Physiol 1998;78:163-9. 